\title{
Estudio de métodos de limpieza sobre yeserías medievales
}

\author{
Eva Vivar García ${ }^{a}$, Ana Isabel Calero-Castillo ${ }^{a}$ y Ana García Bueno ${ }^{a}$
}

${ }^{a}$ Departamento de Pintura. Facultad de Bellas Artes. Universidad de Granada. Avd. de Andalucía, s.n. CP. 18026. evavivargarcia@gmail.com, anacalero@ugr.es; $\underline{\text { anagar@ugr.es }}$

\begin{abstract}
Resumen
El empleo de yeso en revestimientos arquitectónicos decorativos ha sido frecuente en la historia, debido tanto a la presencia de abundantes yacimientos, como a las características de éste. En la península ibérica se ha empleado en elementos decorativos (cornisas romanas, yeserías medievales, pinturas murales...), destacando los revestimientos elaborados en periodo medieval, denominados yeserías, presentes en importantes monumentos como la Alhambra de Granada o el Real Alcázar de Sevilla. En la actualidad estos revestimientos presentan graves problemas de conservación como los repolicromados o encalados, que son muy perjudiciales porque ocultan la policromía original, e incluso pueden producir su pérdida definitiva. A esto se une la escasez de estudios especificos de tratamientos de limpieza adecuados para estas obras. Por ello, este trabajo aborda una primera investigación sobre métodos de limpieza en revestimientos con esta problemática; partiendo de tratamientos empleados de manera tradicional, tales como métodos físicos (bisturí) y métodos químicos (empacos de algodón con disolventes), pero también adaptando otros tratamientos de reciente incorporación como geles de polisacáridos o éteres de celulosa como vehículo del disolvente. Los resultados obtenidos establecen que geles, como el alga roja o éteres de celulosa, son eficaces para la limpieza de encalados y repolicromados en revestimientos de yeso.
\end{abstract}

Palabras clave: limpieza, revestimiento, yesería, repolicromado, conservación, restauración, patrimonio, medieval, encalado.

\begin{abstract}
The use of gypsum in decorative architectural facing has been very usual in the history, owing to the presence of plentiful deposits and the features of this one. In the Iberian Peninsula, gypsum has been used in decoratives elements (romans cornices, medieval platerwork, walls paintings...), the gypsum facing manufacturated in the Middle Ages stand out, named plasterwork, which are present in important monuments such as the Alhambra in Granada or the Real Alcazar of Seville. Currently, these plastework present serius conservation problems such as repolychromed or whitewash, which are damaging since they hide the original polycromy and even they can produce its definitive loss. In addiction to these problems it joins the lack of specific studies of cleaning treatments more suitable for these Works. Therefore, a first investigation on cleaning methods to be used in coatings with this problem is adressed. Starting from treatments used in a traditional way, such as physical methods (scalpel) and chemical methods (cotton poultices with solvents), but also adapting other recently incorporated treatments such as polysaccharide gels or cellulose ethers as a solvent vehicle. The results obtained allow to establish that the use of gels such as red alga, cellulose ethers and acrylic acid are effective for cleaning whitewash and repoliychromed in gypsum facing.
\end{abstract}

Keywords: cleaning, facing, plasterwork, repolychromed, conservation, restoration, heritage, medieval, calcimine. 


\section{Introducción}

Desde la antigüedad el yeso ha sido uno de los materiales empleados como elemento de acabado con una clara función decorativa, esto ha estado favorecido tanto por la presencia de abundantes yacimientos de este material en aquellas regiones donde se ha empleado, como por las características propias de este (materia prima de bajo coste, fácil preparación y uso entre otras cualidades) (Rubio, 2010). En el empleo de este material destacan especialmente los revestimientos de yeso elaborados en la Edad Media, denominados yeserías. Del periodo de ocupación musulmana encontramos ejemplos como la Mezquita de Córdoba, el Alcázar de Sevilla o La Alhambra de Granada, entre otros, práctica que se extenderá, tras la Reconquista, por los reinos cristianos como es apreciable en las yeserías de la Sinagoga del Tránsito y de Santa María la Blanca de Toledo, así como en autores como Jerónimo del Corral y Luis Cabello en el siglo XVI (Bruquetas, 1994).

En la actualidad, en lo que a conservación se refiere, la preservación de este tipo de revestimientos presenta una gran complejidad debido a la presencia de encalados, repolicromados e intervenciones de restauración inadecuadas que ocultan la riqueza y delicadeza del color de la obra original. La limpieza y recuperación de su color es una operación compleja ya que, en muchas ocasiones, los estratos inferiores y originales se encuentran muy descohesionados y degradados como consecuencia de las intervenciones posteriores. A ello se une la escasez de estudios sobre los tratamientos de limpieza a emplear, lo que ha conllevado que muchas intervenciones se hayan efectuado de manera inadecuada, y que como consecuencia se hayan perdido parcial o completamente los restos de color original.

Dada la extensión del tema a estudiar y teniendo en cuenta estas consideraciones, este proyecto propone llevar a cabo un estudio encaminado a solventar este tipo de problemática, efectuando una selección de productos y tratamientos de limpieza a testar sobre una serie de probetas que simulan yeserías medievales. De este modo se podrán evaluar los aspectos positivos y negativos de cada uno de ellos, así como abrir una nueva línea de investigación que permita desarrollar nuevos tratamientos que mejoren los resultados de los ya existentes.

\section{Materiales y métodos}

\subsection{Estudio experimental mediante elaboración de supuestos}

\subsubsection{Elaboración de probetas identificativas de yeserías medievales}

Para la realización de las pruebas de limpieza se parte de probetas de ensayo que reproducen yeserías de época medieval. Todas las probetas han sido realizadas tomando como base ladrillos de arcilla cocida de fabricación industrial

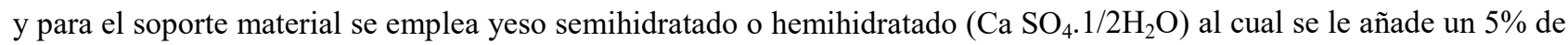
hidróxido de calcio $\mathrm{Ca}\left(\mathrm{OH}_{2}\right)$. Para la policromía se efectúa una selección de los pigmentos y aglutinantes más comunes en este periodo, teniendo en cuenta los datos obtenidos de los estudios precedentes efectuados por nuestro equipo en el Real Alcázar de Sevilla (Calero, 2016; Calero et al., 2017), el Oratorio de la Madraza de Yüsuf I en Granada (García et al., 2010) o el Cuarto Real de Santo Domingo en la misma ciudad (García y Medina, 2004). En total se elaboran doce probetas de ensayo (Tabla 1, Fig. 1).

Tabla 1. Composición de las probetas elaboradas, identificativas de yeserías medievales

\begin{tabular}{|c|c|c|c|c|c|c|c|c|c|c|c|c|}
\hline $\mathrm{N}^{0}$ de Probeta & $1 \mathrm{~A}$ & 1B & $2 \mathrm{~A}$ & 2B & $3 \mathrm{~A}$ & 3B & $4 \mathrm{~A}$ & 4B & $5 \mathrm{~A}$ & 5B & $6 \mathrm{~A}$ & $6 \mathrm{~B}$ \\
\hline Base común & \multicolumn{12}{|c|}{ Yeso semihidratado o hemihidratado $+5 \%$ de hidróxido de calcio } \\
\hline Aglutinante & Cola animal & Cola animal & Goma arábiga & Goma arábiga & Cola animal & Cola animal & Goma arábiga & Goma arábiga & Goma arábiga & Cola animal & Goma arábiga & Cola animal \\
\hline Pigmento & Malaquita & Ocre natural & Malaquita & Ocre natural & Cinabrio & Azurita & Cinabrio & Azurita & $\begin{array}{c}\text { Rojo de plomo } \\
\quad+\text { cinabrio }\end{array}$ & $\begin{array}{c}\text { Rojo de plomo } \\
\quad+\text { cinabrio } \\
\end{array}$ & Cinabrio & Cinabrio \\
\hline
\end{tabular}


PROBETA $1 \mathrm{~A}$

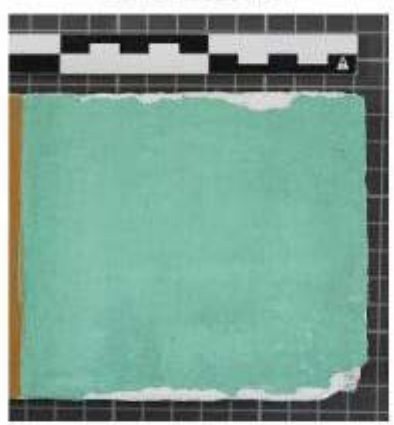

POLICROMIA

Aglutinante: cola animal

Pigmento: malaquita
PROBETA $1 \mathrm{~B}$

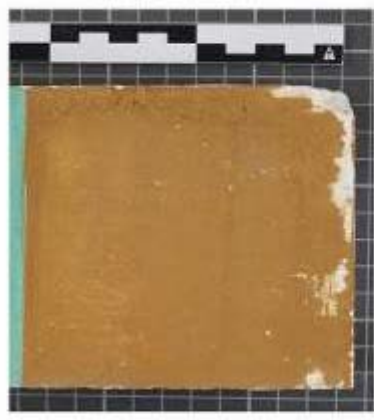

POLICROMIA

Aglutinante: cola animal

Pigmento: ocre natural
PROBETA 2A

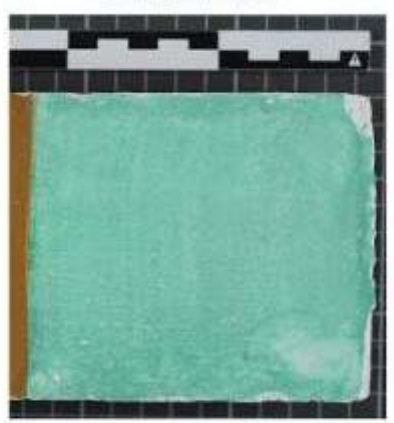

POLICROMIA

Aglutinante: goma arábiga

Pigmento: malaquita
PROBETA 2B

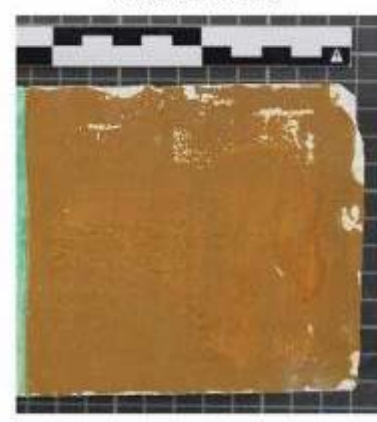

POLICROMIA

Aglutinante: goma arábiga Pigmento: ocre natural

Fig. 1 Ejemplo de las probetas empleadas en el estudio de limpieza

\subsubsection{Inducción de las alteraciones}

Realizada la revisión bibliográfica, se seleccionan aquellas alteraciones que son más comunes en este tipo de obras, y que son aplicadas sobre las probetas:

- Encalado: Capa de cal cuyo objetivo era el de ocultar los colores que estas tenían por no considerarse acordes a la estética neoclasicista (Chávez, 2004) (Fig. 2).

- Repolicromado: Capas de color aplicadas sobre las yeserías medievales con una triple función: cambiar el color original, recuperar el color degradado u oculto por encalados o dotar nuevamente de color a las yeserías encaladas. Históricamente, han sido elaborados empleando como aglutinantes aceites (aceite de linaza), resinas terpénicas (García et al., 2010) y (Rubio, 2010), o cola animal como ocurre en el patio de las doncellas del Real Alcázar de Sevilla (Calero et al., 2017). Para este trabajo se han seleccionado, por un lado para la realización del repolicromado de temple el aglutinante cola animal y el pigmento tierra roja, y por otro lado para la realización del repolicromado de óleo el aglutinante aceite de linaza con pigmento ocre (García et al., 2010).
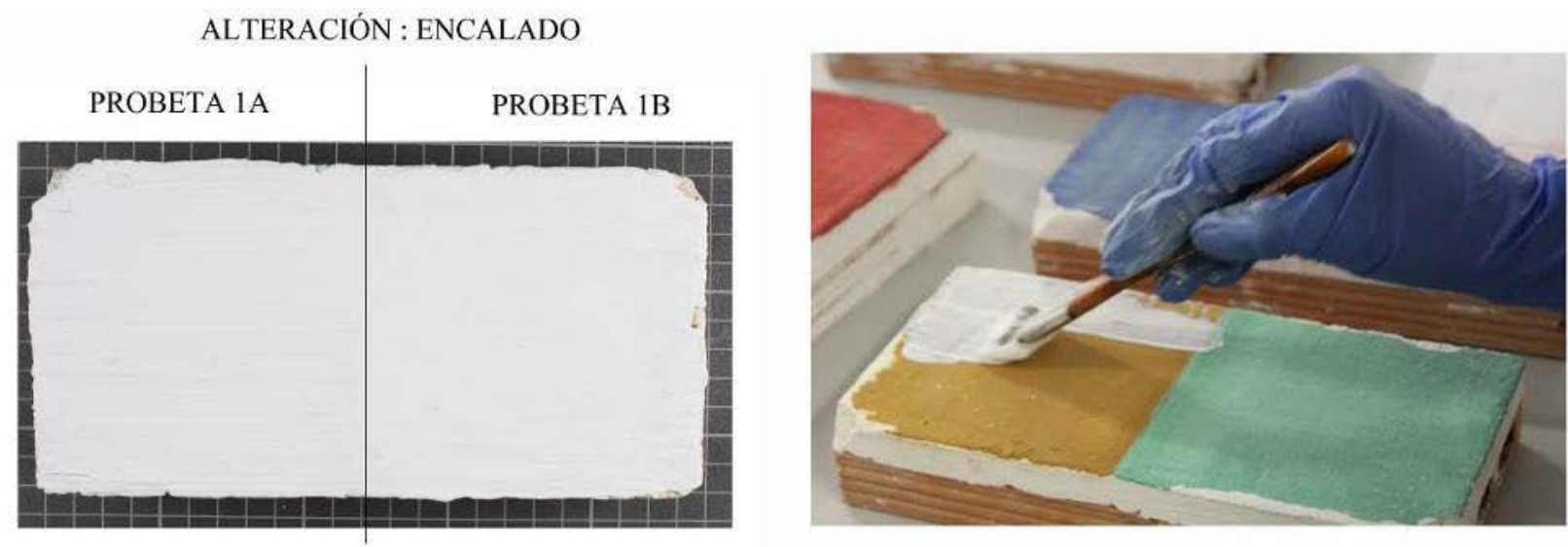

Fig. 2 Ejemplo de inducción de una de las alteraciones: encalado

\subsubsection{Selección de los tratamientos de limpieza a testar}

Realizada la revisión bibliográfica, se efectúa una selección de los tratamientos de limpieza a testar para la eliminación de repolicromados y encalados. Los tratamientos de tipo físico se han seleccionado por el control y su eficacia en este tipo de alteraciones, y en los casos que se ha considerado necesario, se ha aplicado este tratamiento como complemento a los demás seleccionados, que son de tipo químico. En los tratamientos de tipo químico se han escogido empacos con pulpa de celulosa y algodón, geles elaborados con ácidos acrílicos (®Carbogel), agentes polisacáridos (®)Gellano 
Kelcogel) alga roja (®Agar-Agar), metilcelulosa e hidroxipropilceculosa (®klucel G) recomendados por autores como Borgioli (2001) y Sanchez (2012) por ser de utilidad en su aplicación sobre superficies sensibles al agua. Los disolventes seleccionados han sido agua, agua y acetona (75:25) y agua y alcohol (75:25), para la limpieza de repolicromado de temple de cola animal y encalado, y para la eliminación de repolicromados de óleo los disolventes escogidos han sido Triple A ( agua, acetona y alcohol (1:1:1), White Spirit y acetona en las proporciones (75:25) y (50:50) (Tabla 2). Esta selección se ha basado en los estudios realizados por autores como Hubbard (1993), Wolbers (2000), y Giordano y Cremonesi (2019), entre otros.

Tabla 2. Tratamientos de limpieza seleccionados

\begin{tabular}{|c|c|c|c|}
\hline \multirow[t]{2}{*}{ Tratamientos de limpieza } & $\begin{array}{l}\text { Alteración: } \\
\text { encalado }\end{array}$ & $\begin{array}{l}\text { Alteración: Repolicromado de } \\
\text { temple de cola de conejo }\end{array}$ & $\begin{array}{l}\text { Alteración: } \\
\text { repolicromado de óleo }\end{array}$ \\
\hline & Disolventes empleados en cada tratamiento & Disolventes empleados en cada tratamiento & Disolventes empleados en cada tratamiento \\
\hline \multicolumn{4}{|l|}{ Mecánicos ( Bisturí) } \\
\hline Empacos de pulpa de celulosa & Agua & Agua & Triple A \\
\hline Papetas AB57 & & & $($ Agua + Acetona + Alcohol) (1:1:1) \\
\hline Hisopo & & Triple A & \\
\hline Geles: & Agua + Acetona (75:25) & $($ Agua + Acetona + Alcohol $)(1: 1: 1)$ & White Spirit + Acetona \\
\hline Ácido acrílico & & & $(75: 25)$ \\
\hline Polisacárido & & Agua + Acetona $(75: 25)$ & \\
\hline Alga roja & Triple A & & White Spirit + Acetona \\
\hline Hidroxipropilcelulosa & $($ Agua + Acetona + Alcohol) (1:1:1) & Agua + Alcohol (75:25) & $(1: 1)$ \\
\hline Metilcelulosa & & & \\
\hline
\end{tabular}

\subsection{Evaluación de los tratamientos}

\subsubsection{Elaboración de las plantillas para limpieza}

Con el objetivo de ser muy rigurosos en la aplicación y evaluación de los tratamientos de limpieza, se decide emplear plantillas de acetato siguiendo la metodología expuesta por el Instituto del Patrimonio Cultural de España (IPCE), dentro del Proyecto Nanomaterials for the Restoration of Works of art - EU project (Nanorestart). Cada una de las plantillas está adaptada a cada probeta en la que se efectúan aberturas con una dimensión de $2 \times 2 \mathrm{~cm}$ sobre las que evaluar los tratamientos de limpieza seleccionados para el trabajo (Fig. 3).
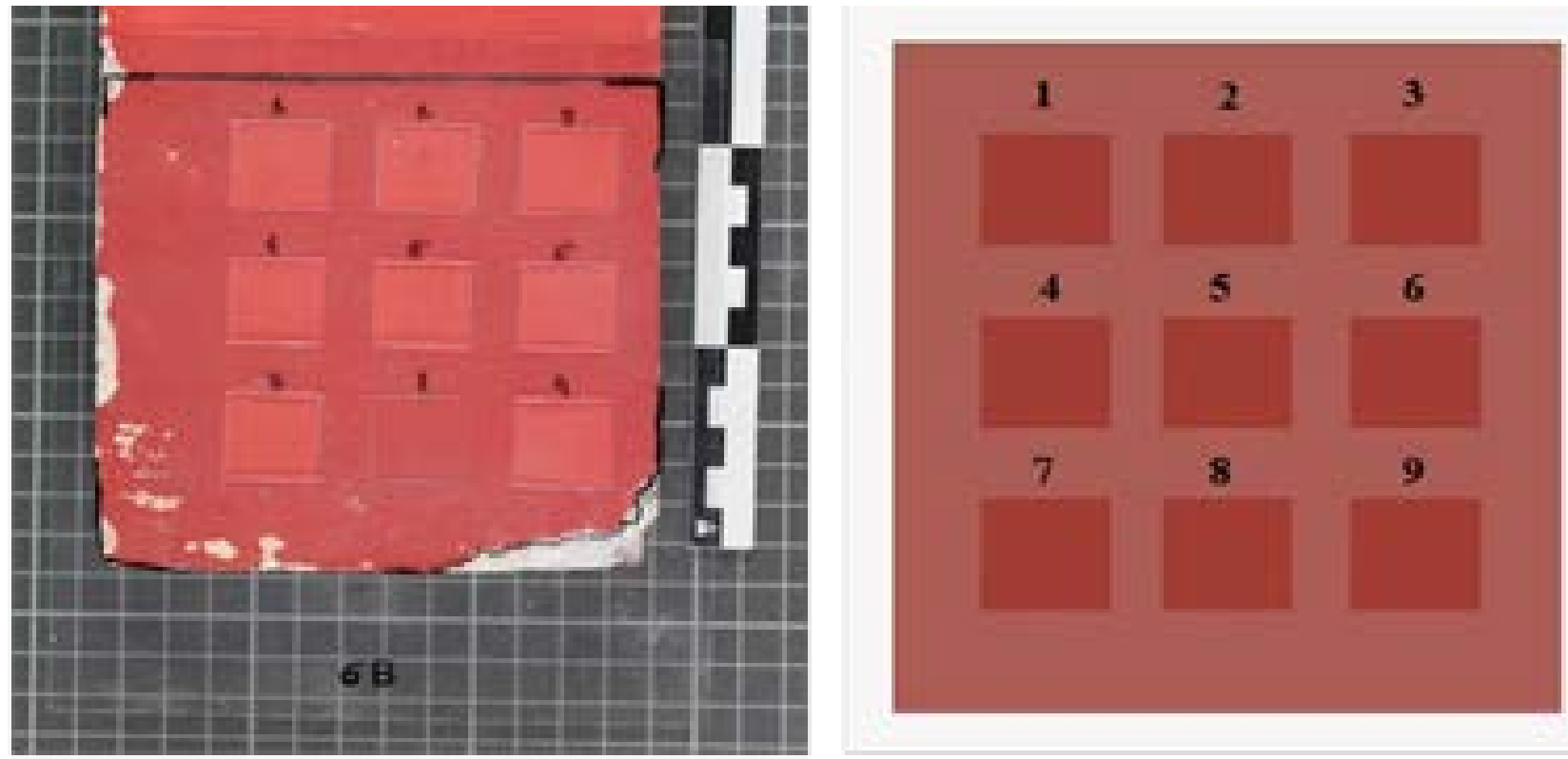

Fig. 3 Ejemplo de plantilla de limpieza elaborada para una de las probetas del estudio 


\subsubsection{Documentación fotográfica}

Se realizan tomas fotográficas generales, parciales y de detalle con el equipo Canon EOS 1200D en mesa de reproducción en tres momentos diferentes del estudio: 1. Estado inicial de la probeta, 2. Apariencia de la probeta tras la inducción de alteraciones (repolicromados y encalados), 3. Estado final de la probeta tras la aplicación de cada uno de los métodos de limpieza. Igualmente se han documentado aquellas particularidades que han aparecido en la aplicación de los tratamientos.

\subsubsection{Microscopía estereoscópica}

La imagen microscópica de la superficie se toma como referencia del estado inicial y final de la superficie policromada de las probetas estudiadas. Para este análisis se empleó un microscopio con haz óptico paralelo NIKON SMZ 1000 con capacidad para microfotografía gracias a la cámara integrada en el dispositivo. Este microscopio está equipado con un factor de zoom lo que permite valorar y cuantificar visualmente los efectos de los tratamientos aplicados (Fig. 4).

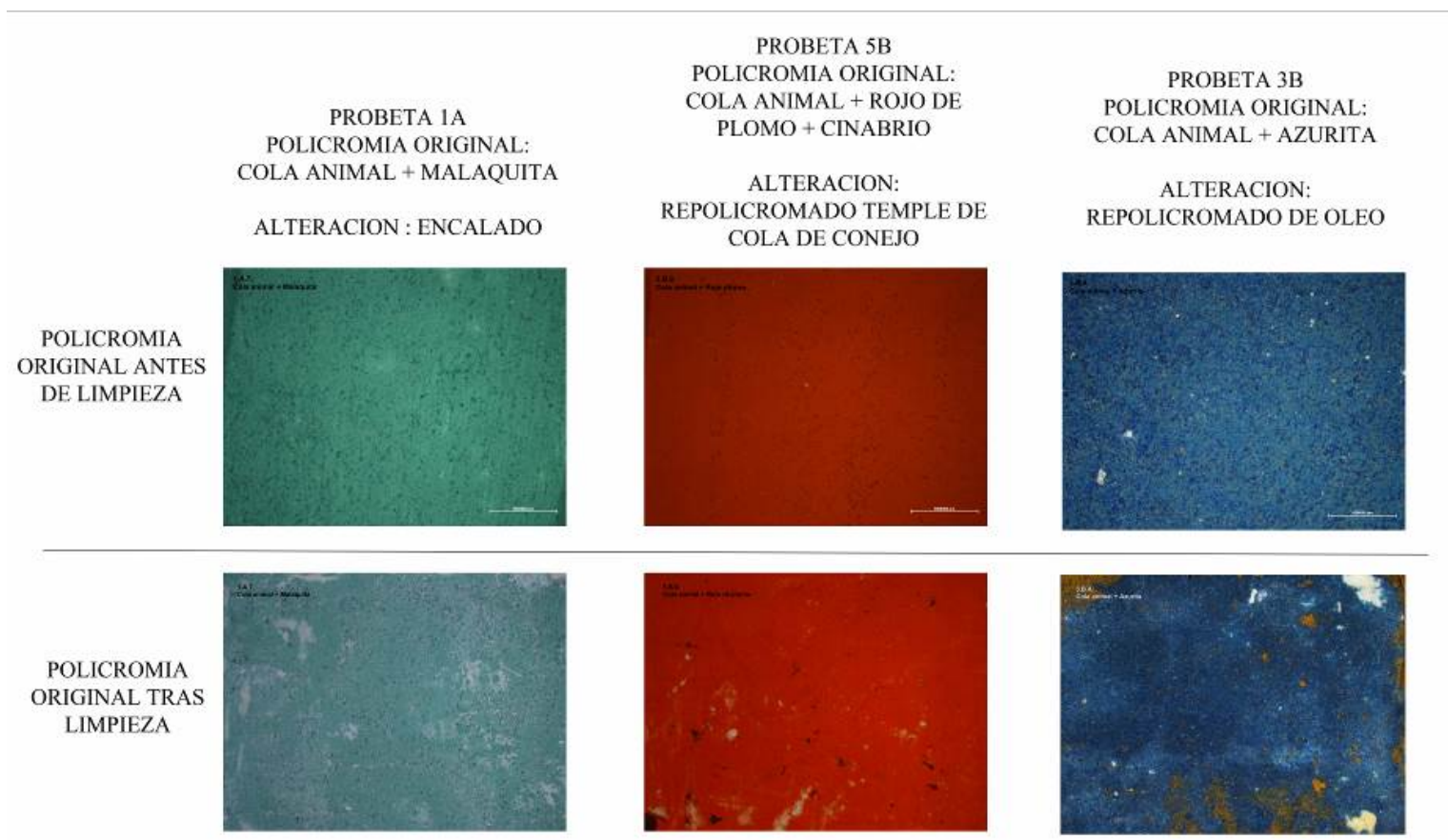

Fig. 4 Comparación del estado de la policromía original antes y después de los tratamientos de limpieza, mediante microscopia estereoscópica

\subsubsection{Estudio de fotogrametría}

Con el fin de evaluar de manera objetiva la eliminación de las diferentes capas superpuestas sobre la policromía original, a partir de la documentación fotográfica obtenida tras la inducción de las alteraciones, se elaboran modelos fotogramétricos empleando el programa AUTODESK RECAP. Este permite reproducir modelos tridimensionales de las probetas a partir de fotografías, por lo que se trata de una técnica no destructiva ni invasiva. El objetivo es estudiar la superficie de la obra antes y después de aplicar el tratamiento de limpieza, para determinar aquellas áreas en las que el tratamiento haya sido más efectivo. Para efectuar esta evaluación se ha seguido la metodología expuesta por López, García y Medina (2018) que se basa en la comparación de los modelos fotogramétricos antes y después de aplicar los tratamientos de limpieza, mediante el programa CLOUDCOMPARE. Este programa compara las distancias entre las mallas de cada modelo, obteniendo un mapa de color que va desde el verde, zona en la que coinciden las superficies de ambos modelos comparados, hasta rojo que indican que hay una mayor distancia entre los dos modelos. Por lo tanto la superficie de color verde se corresponde con el repolicromado, y las zonas de limpieza presentan una gama de color del amarillo, allí donde se ha eliminado el repolicromado, hasta el color rojo que se corresponde con las zonas donde se ha eliminado parte de la policromía original. 


\subsubsection{Plantilla de evaluación}

A fin de determinar que tratamientos han sido más efectivos, se crea una plantilla de evaluación cuantitativa. Para ello se evaluarán una serie de parámetros, valorándolos del 0 al 10, siendo 0 nada y 10 todo, respetivamente (Tabla 3 )

Tabla 3. Plantilla de evaluación cuantitativa de la eficacia de los tratamientos de limpieza

\begin{tabular}{|c|c|c|c|c|c|c|c|c|}
\hline \multicolumn{9}{|c|}{$\mathrm{N}^{\circ}$ DE PROBETA } \\
\hline $\begin{array}{c}\text { Parámetros evaluados } \\
\mathrm{N}^{\circ} \text { de Prueba }\end{array}$ & $\begin{array}{l}\text { Alteración de la } \\
\text { policromia original }\end{array}$ & $\begin{array}{l}\text { Grado de eliminación } \\
\text { de la alteración }\end{array}$ & $\begin{array}{l}\text { Resistencia de la } \\
\text { capa de alteración }\end{array}$ & $\begin{array}{l}\text { Permanencia de } \\
\text { restos de la alteración }\end{array}$ & $\begin{array}{c}\text { Residuos del } \\
\text { tratamiento }\end{array}$ & $\begin{array}{c}\text { Toxicidad } y / o \\
\text { peligro }\end{array}$ & $\begin{array}{l}\text { Penetración disolvente } \\
\text { en la capa de alteración }\end{array}$ & $\begin{array}{l}\text { Tiempo de } \\
\text { actuación }\end{array}$ \\
\hline \multicolumn{9}{|l|}{ Disolvente } \\
\hline \multicolumn{9}{|l|}{ 1. Empaco pulpa de algodón } \\
\hline \multicolumn{9}{|l|}{ 2. Gel de metilcelulosa } \\
\hline \multicolumn{9}{|l|}{ 3. Empaco de pulpa de celulosa } \\
\hline \multicolumn{9}{|l|}{ 4. Gel de ácido acrílico } \\
\hline \multicolumn{9}{|l|}{ 5. Gel de polis acárido } \\
\hline \multicolumn{9}{|l|}{ 6. Hisopo } \\
\hline \multicolumn{9}{|l|}{ 7. Gel de alga roja } \\
\hline \multicolumn{9}{|l|}{ 8. Gel de hidroxipropilcelulosa } \\
\hline 9. Fibra de vidrio y bisturí & & & & & & & & \\
\hline
\end{tabular}

\section{Resultados}

\subsection{Documentación fotográfica y microscopía estereoscópica}

Partiendo de la comparación de la documentación fotográfica y de las imágenes de microscopia estereoscópica, es posible evaluar visualmente los resultados obtenidos tras las limpiezas. Con los datos obtenidos, se establece que en el caso de la eliminación de encalados (Probeta 4A) y los repolicromado de temple (Probeta 4B), los tratamientos más efectivos han sido el uso de geles de ácido acrílico, de alga roja y de éteres de celulosa empleando como disolventes agua y agua y acetona (75:25) (Fig. 6). Estas limpiezas se corresponden con los espacios de las plantillas de limpieza 4, 7 y 8 respectivamente, ya que se mantiene gran parte de la policromía original. Por otra parte, los métodos tradicionales como el bisturí o los empacos de pulpa de celulosa con disolventes como agua y agua y acetona (75:25), correspondientes a los huecos 3 y 9, han resultados menos efectivos en la eliminación de esas alteraciones, pues la capa de policromía original se pierde casi por completo. En el caso de la limpieza de repolicromado de óleo (Probeta 3B, Fig. 6) encontramos que los tratamientos de gel de alga roja y de éteres de celulosa también lo han sido efectivos aquí, como se aprecia en las limpiezas 7 y 8 del repolicromado de óleo, pero también han funcionado los geles de polisacáridos y los empacos de algodón y pulpa de celulosa correspondientes a los huecos de limpieza 5, 1 y 3 respectivamente, en este caso los disolventes empleados más efectivos han sido White Spirit y acetona en la proporción 50:50 y 75:25 (Fig. 5).
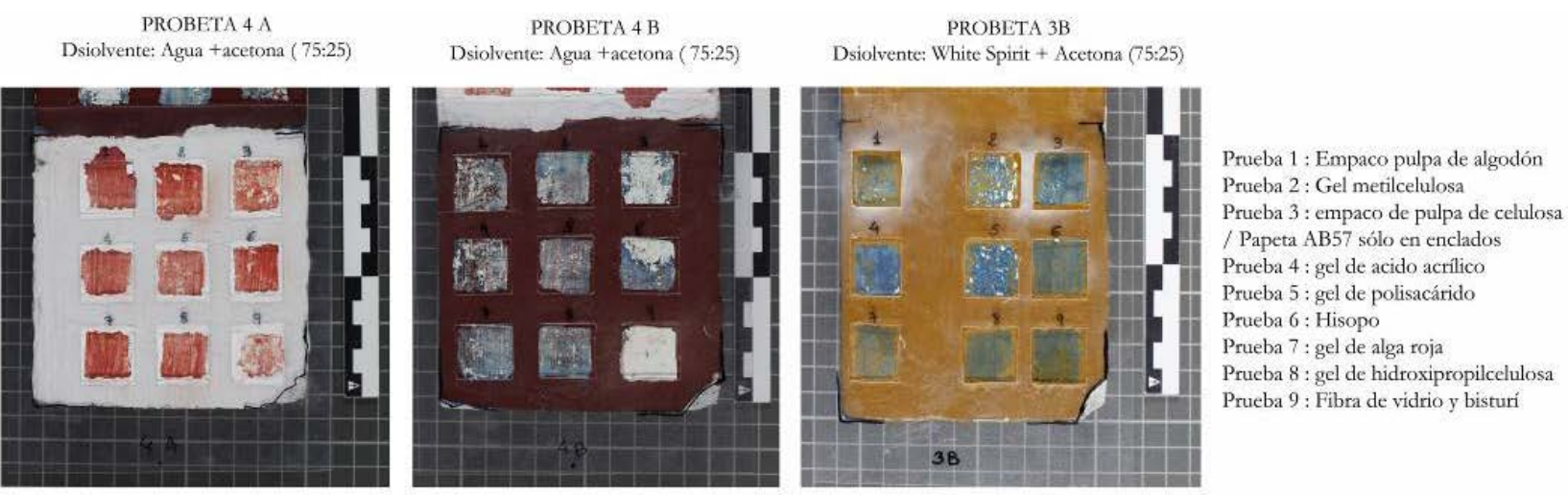

Fig. 5 Ejemplos de limpiezas de los tres tipos de alteraciones analizados en este estudio 


\subsection{Modelos fotogramétricos}

Tras comparar los modelos fotogramétricos, se puede establecer que para la limpieza de repolicromado de óleo, los geles de ácido acrílico, de polisacárido y de alga roja, aplicados todos ellos con la mezcla de disolventes White Spirit y acetona (75:25), han sido los más efectivos, estos tratamientos de limpieza se corresponden con los huecos de limpieza 4, 5, 7 y 8 respectivamente, de la plantilla de limpieza de la probeta 3B (Fig. 6). En estos tratamientos de limpieza se observa el color amarillo, indicativo de que la limpieza ha eliminado el repolicromado pero no la capa de policromía original. Mientras en otros huecos, de la plantilla de limpieza, donde se han aplicado otros tratamientos de limpieza, se observa el color rojo, indicativo de que la limpieza ha eliminado el repolicromado pero también la capa de policromía original. Este color rojo también se observa en los huecos de limpieza de la plantilla de la probeta $3 \mathrm{~A}$, y por ende muestra que en la probeta 3A los tratamientos de limpieza han sido menos efectivos (Fig. 6).

De igual manera se han comparado los modelos fotogramétricos para el resto de de alteraciones estudiadas, obteniendo que, para la limpieza de encalado, los tratamientos más efectivos son el gel de alga roja y el gel de hidroxipropilcelulosa aplicados cada uno de ellos con los disolventes agua y agua y acetona (75:25), y la Papetta AB57. En caso de la limpieza de repolicromado de temple, el gel de alga roja, el gel de hidroxipropropil celulosa y el gel de ácido acrílico empleados cada uno de ellos con los disolventes agua y agua y acetona (75:25), son los tratamientos que aportan mejores resultados. Esto se corresponde con los datos obtenidos en la comparación de las imágenes de microscopia estereoscópica.

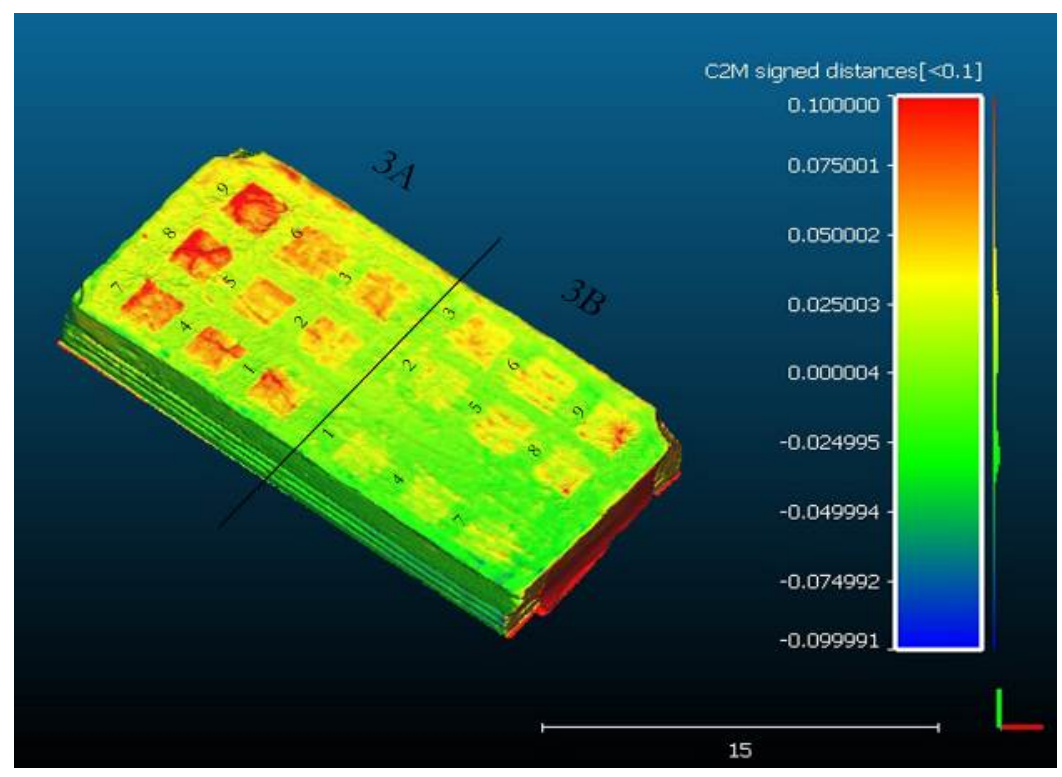

Fig. 6 Ejemplo de comparación de modelos fotogramétricos mediante CloudCompare

\subsection{Plantilla de evaluación}

A partir de la fichas de evaluación, donde se cuantifica la eficiencia de las limpiezas en base a unos parámetros (Tabla 3), se elaboran unos gráficos, que nos permiten (visual y cuantitativamente), determinar que tratamientos han sido más efectivos. Los parámetros son valorados de 0 a 10 , siendo 0 que no se observa nada ese parámetro y 10 que se observa en su totalidad el parámetro. La figura 7 es un ejemplo de ello, podemos ver la valoración de los tratamientos de limpieza de repolicromado de óleo con la mezcla de disolventes white spirit y acetona (75:25). Se analiza este disolvente debido a que ha sido uno de los más efectivos en la limpieza de repolicromado de óleo, en base a los resultados de fotogrametría y microscopia estereoscópica. Los resultados obtenido mediante este método de evaluación establecen que los geles de ácido acrílico, de polisacárido, el alga roja y el de hidroxipropilcelulosa son los que presentan menor toxicidad. En el caso del gel de polisacárido requiere de menor tiempo de actuación para reblandecer el repolicromado (alteración inducida), y es posible eliminar el repolicromado casi en tu totalidad, sin dejar a penas restos de éste sobre la policromía original. Por otra parte el gel de ácido acrílico penetra más en la capa en la capa de 
repolicromado, por lo que presenta menos resistencia, y es más fácil elimina la alteración. Por otro lado parte los geles de alga roja e hidroxipropilcelulosa requieren de mayor tiempo de actuación para reblandecer la alteración y eliminarla, además de que el tratamiento de gel de hidroxipropilcelulosa deja residuos propios, a pesar del papel japonés empleado como protección, estos residuos del gel son difíciles de eliminar y pueden dañar la policromía original.

Limpieza repolicromado de óleo con disolvente White Spirit + Acetona (3:1)

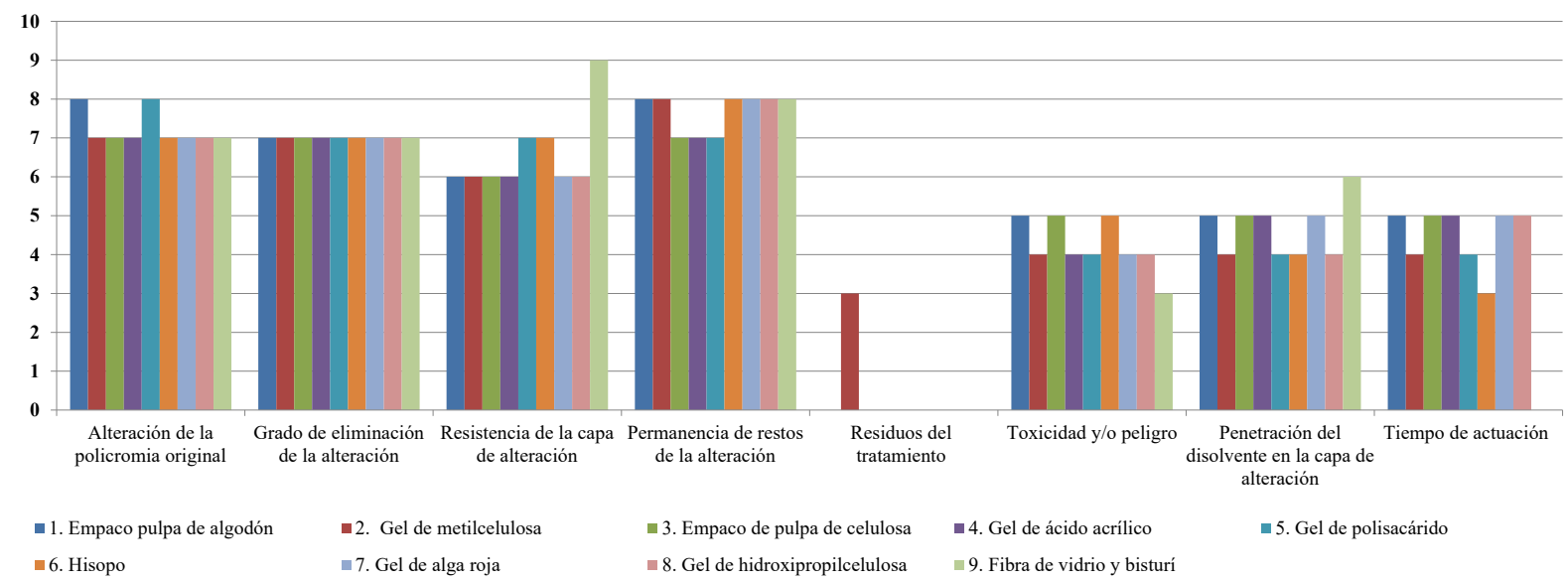

Fig. 7 Limpieza repolicromado de óleo con White Spirit + Acetona (3:1)

Estos gráficos han sido elaborados para todos los supuestos estudiados. En el caso de la limpieza de repolicromado de temple se obtiene que lo geles de ácido acrílico y polisacárido requieren de mayor tiempo de actuación, y no es posible eliminar el repolicromado sin dañar la policromía original. Por otra parte, los geles de alga roja e hidroxipropilcelulosa demuestran ser más efectivos para eliminar el repolicromado sin dañar la policromía original, y requieren de menor tiempo de actuación. En el caso de los encalados, los resultados son similares a los de la limpieza de repolicromado, aunque los tratamientos de empacos de algodón también son efectivos, sin embargo el tiempo de actuación que requieren es muy elevado, y es más difícil controlar el grado de penetración del disolvente.

\section{Conclusiones}

La consulta bibliográfica ha permitido conocer la técnica y los materiales empleados en la realización de las yeserías medievales, determinar cuáles son principales alteraciones que afectan a la conservación del color original (repolicromados y encalados), así como los tratamientos que tradicionalmente se han empleado en obras que presentan esos problemas de conservación. Esta información ha permitido comenzar una investigación a partir de supuestos (probetas de yeso policromadas sobre las que se inducen las diferentes alteraciones) sobre las cuales realizar diferentes pruebas de limpieza. Unido a ello, se ha desarrollado una metodología basada en la elaboración de fichas identificativas, documentación fotográfica, examen por microscopía estereoscópica y comparación de modelos fotogramétricos entre otros métodos. Esta metodología ha demostrado ser válida para determinar cuáles han sido los tratamientos más efectivos y se han extraído las siguientes conclusiones:

- En la limpieza de encalados y repolicromados de temple, los tratamientos adaptados, como los éteres de celulosa (hidroxipropilcelulosa) y el alga roja, aplicados con agua y agua y acetona (75:25), han sido los más efectivos.

- En la limpieza de repolicromados de óleo, los tratamientos más efectivos han sido los geles de ácido acrílico (®Carbogel), de polisacárido ( ${ }^{\circledR}$ Gellano kelcogel), aplicados con la mezcla de disolventes White Spirit y acetona (75:25).

- Así, este proyecto supone un punto de partida para una investigación más completa, en la que se ampliará tanto el número de tratamientos como de las pruebas de evaluación. Una vez en este punto y con los datos obtenidos, se realizarán pruebas de los que hayan demostrado ser más efectivos sobre obra real con el objetivo de determinar aquellos que garanticen mayor eficacia para la limpieza de este tipo de obras. 


\section{Referencias}

Autodesk. RecapPhoto (2019). Recuperado de https://www.autodesk.es/

Bogiorli, L. (2001). Espesantes para disolventes. Espesantes para soluciones acuosas. Kermes, (44), Recuperado de https://www.geiic.com/wp-content/uploads/2008/01/Espesantes.pdf

Bruquetas, R. (1994). El trabajo de la yesería en España. En T. Gómez (Ed.), La obra en yeso repolicromado de los Corral de Villalpando (pp.76-83). Madrid: Seamer.

Calero, A. I. (2016). Materiales, técnicas y procedimientos en la decoración arquitectónica. Aplicaciones a la conservación y restauración de las yeserías del Patio de las Doncellas del Real Alcázar de Sevilla. Tesis doctoral. Granada: Universidad de Granada.

Calero, A. I., García, A., López, O., y Medina, V. J. (2017). La policromía original de las yeserías del Patio de las Doncellas del Real Alcázar de Sevilla. Materiales constitutivos y técnicas de ejecución. Arqueología y Territorio Medieval, 24, 255-290. doi: 10.17561/aytm.v24i0.9

Chávez, M. (2004). El Alcázar de Sevilla en el siglo XIX. Sevilla: Patronato del Real Alcázar de Sevilla.

CloudCompare( 2018). Recuperado de: https://www.danielgm.net/cc/

García, A., y Medina, V. J. (2004). The Nasrid plastework at "qubba Dar al-Manjara I-Kubra" in Granada: characterisation of material and techniques. Journal of cultural Heritage, 5(1), 75-89.

García, A., Hernández, A., y Medina, V. J. (2010). La yeserías del Oratorio de la Madraza de Yusuf, Granada, aportaciones de la documentación gráfica a la determinación de las zonas originales y añadidos en el estudio preliminar. Al-Qantara (AQ), 31(1), 257-267.

García, A., Medina, V. J., y González, A. (2010). La policromía de yeserías del Oratorio de la Madraza de Yusuf, Granada. Primeras aportaciones del estudio de materiales para la localización de zonas originales y añadidos. Al-Quantara (AQ), 31(1), $245-256$.

Giordano, A., y Cremonesi, P. (2019). Gel rigidi polisaccaridici per il trattamento dei manufatti artistici. Saonara: Il Prato.

Hubbard, C. (1993, April). Alabaster Conservation. En Victoria and Albert Museum, 7. Recuperado de http://www.vam.ac.uk/content/ journals/conservation-journal/issue-07/alabaster-conservation/

Instituto de Patrimonio Cultural de España (2018, 3 de abril). Proyecto Nanorestart - EU Project (Nanomaterials for the Restoration of Works of Art). [Video Facebook Instituto del Patrimonio Cultural de España (IPCE)]. Recuperado de https://www.facebook.com/ipcepatrimonio/videos/1618282464893497/UzpfSTEwMDAwMDA0MjgwNDc3NToyNzkxMzU5N TUwODc1NDQ0/

López, T., García, A., y Medina, V. J. (2018). New methodology for the assessment of cleaning treatments. Applications of photogrammetry for restoration. Journal of Cultural Heritage 30, 117-123. Doi: https://doi.org/10.1016/j.culher.2017.09.019

Rubio, R. F. (2010). Yeserías de la Alhambra. Historia, técnica y conservación. Granada: Universidad de Granada.

Sánchez, A. (2012). Restauración de pinturas de Arte: Pinturas de Caballete. Madrid: Akal S.A.

Wolbers, R. (2000). Cleaning painted surfaces. Aqueous methods. Londres: Archetype Publications. 